Digilec 8 (2021), pp. 1-20

Fecha de recepción: 20/07/2021

Fecha de aceptación: 30/07/2021

DOI: https://doi.org/10.17979/digilec.2021.8.0.8633
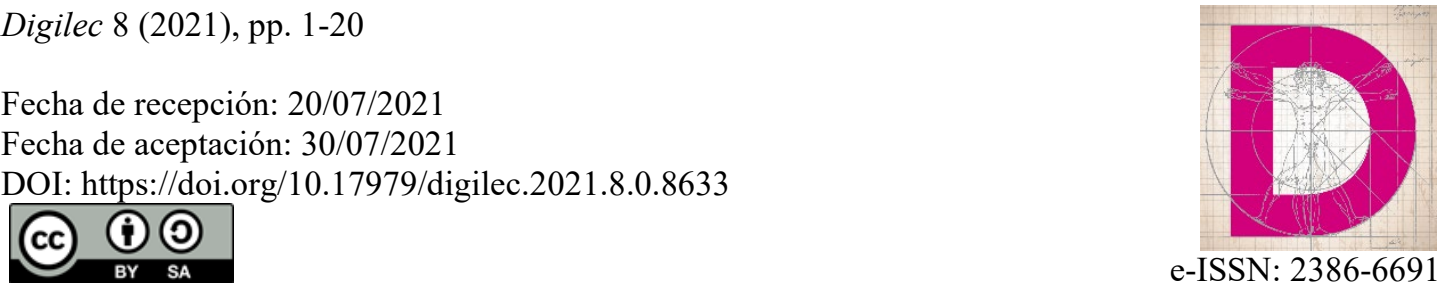

\title{
SIGUIENDO LAS "REGLAS DEL JUEGO": LA ALEATORIEDAD E INDETERMINACIÓN COMO CASILLA DE SALIDA DE LA COMPOSICIÓN EN EL AULA
}

\author{
FOLLOWING THE "GAME RULES": RANDOMNESS AND \\ INDETERMINACY AS A STARTING POINT TOWARDS \\ COMPOSITION IN THE CLASSROOM
}

\author{
Vicente CASTRO ALONSO* \\ Universidade da Coruña \\ Orcid: https://orcid.org/0000-0001-9817-3783 \\ Aurelio CHAO-FERNANDEZ* \\ Universidade da Coruña \\ Orcid: https://orcid.org/0000-0001-7846-7637 \\ Cristina PÉREZ CREGO* \\ Universidade da Coruña \\ Orcid: https://orcid.org/0000-0001-5937-0047
}

\section{Resumen}

Esta investigación-acción describe y analiza los resultados de una experiencia educativa basada en la composición e interpretación ante público de una pieza musical basada en los principios de la aleatoriedad y la indeterminación. A través de una inmersión históricamente fundamentada, el alumnado realiza un recorrido por las principales coordenadas estéticas de esta vanguardia, diseñando sus propias partituras mediante notación gráfica. El estudio, llevado a cabo con un grupo de estudiantes de $1^{\circ}$ de bachillerato (Galicia, España), se articula en torno a los siguientes objetivos: 1) identificar comportamientos de engagement y participación proactiva; 2) describir y analizar la adecuación idiomática de los productos artísticos; 3) comprobar el grado de asimilación teórico-conceptual; y 4) conocer el grado de aceptación o rechazo de la música aleatoria e indeterminada.

La exploración combina el recurso a instrumentos de recogida de datos cuantitativos (cuestionarios) y cualitativos (observación participante, no participante, en vídeo y análisis documental). Tras detectar las necesidades del grupo, se acomete la planificación

* Facultade de Ciencias da Educación. Universidade da Coruña. Campus de Elviña, s/n. 15071 A Coruña. Email: vicente.castro@udc.es, aurelio.chao@udc.es, cristina.pcrego@udc.es 
de una propuesta de mejora, su evaluación y posterior reflexión acerca de los resultados obtenidos.

La experiencia como juego y la actuación ante público actúan como revulsivo actitudinal, tanto en la participación como en el compromiso colectivo. El alumnado muestra una asimilación interiorizada -tanto conceptual como procedimental- de ambos repertorios, alcanzando resultados sonoros estilísticamente idiomáticos. Por todo ello, la propuesta demuestra su validez pedagógica, favoreciendo la apertura de horizontes culturales del alumnado, así como permitiendo consolidar creaciones artísticas genuinas en el aula de secundaria.

Palabras clave: Composición; educación musical; aleatoriedad; indeterminación; notación gráfica

\begin{abstract}
This action-based research describes and analyzes the results of an educational experience based on composition and public performance of a musical piece based on the principles of randomness and indeterminacy. Through a historically grounded immersion, students take a tour of the main aesthetic coordinates of this avant-garde, designing their own scores using graphic notation. The study, carried out with a 1st year high school student group (Galicia, Spain), is structured around the following objectives: 1) identify behaviors and proactive participation; 2) describe and analyze the idiomatic adequacy of artistic products; 3) check the degree of theoretical-conceptual assimilation; and 4) recognize the degree of acceptance or rejection of aleatory and indeterminate music.

The exploration combines the use of quantitative data collection instruments (questionnaires) and qualitative data (participant and non-participant observation, video and documentary analysis). After detecting the needs of the group, the planning of an improvement proposal is undertaken, its evaluation and subsequent reflection on the results obtained.

The experience as a game and the performance before the public act as an attitudinal trigger, both in participation and in collective engagement. The students show an internalized assimilation -conceptual and procedural- of both repertoires, achieving stylistically idiomatic sound results. Therefore, the proposal demonstrates its pedagogical validity, favoring the opening of the students' cultural horizons, as well as allowing the consolidation of genuine artistic creations in the secondary school classroom.
\end{abstract}

Key Words: Composition; musical education; randomness; indeterminacy; graphic notation 


\section{INTRODUCCIÓN}

La idiosincrasia sociopolítica del pasado siglo fraguó un caleidoscopio de idearios estéticos y artísticos, en ocasiones en franca divergencia. Ejemplo de ello ha sido la contraposición ideológico-conceptual existente entre, por una parte, el rígido estructuralismo de la música serial de primera mitad de siglo XX y, por otra, el incipiente aperturismo de la aleatoriedad y la indeterminación, de la mano de autores estadounidenses como Charles Ives, Henry Cowell, Earle Brown, Christian Wolff, La Monte Young y, especialmente, John Cage (Galiana-Gallach, 2018). Los planteamientos de aleatorios e indeterministas -junto con el auge de la música electroacústica- conducen a la aparición de un nuevo tipo de grafía musical, en el que lo visual cobra una mayor preponderancia (Buj-Corral, 2014): las denominadas partituras gráficas. Su combinación de diseños geométricos, dibujos, fotografías, números, instrucciones textuales, elementos de la notación tradicional o incluso objetos tridimensionales (Weekes, 2016) reflejan el afán gráfico en una "búsqueda de nuevos timbres y posibilidades formales" (GarcíaFernández, 2018: 1770). Este caldo de cultivo implicó la ruptura con la sintaxis tradicional de la tradición previa, consolidando un tipo de sonoridades experimentales y transgresoras, escuchadas por un público habitualmente especialista y/o minoritario. En este aspecto, Frova (2012) explica cómo los patrones de los impulsos cerebrales humanos correspondientes a la audición de este tipo de música suelen ser mucho más aleatorios e impredecibles que en la música clásica tradicional. Ello se traduce, según dicho autor, en experiencias menos satisfactorias o placenteras, ya que nuestro cerebro no encuentra suficientes elementos redundantes a la hora de predecir el desarrollo del discurso sintáctico percibido.

Por nuestra parte, creemos que al igual que sucede con el aprendizaje de un idioma, nuestro oído ha de aclimatarse a la fonética y gramática estudiadas desde la práctica, a través de metodologías activas que favorezcan su asimilación y presumible disfrute. El presente artículo sintetiza una experiencia educativa enmarcada en el ámbito de la Didáctica de la Música en la educación secundaria, a través de una "inmersión" en los mundos sonoros de la aleatoriedad e indeterminación. Continuando con las bases metodológicas e ideológicas de un estudio previo basado en el repertorio serial dodecafónico (Castro Alonso, 2020), esta investigación-acción analiza los beneficios educativos inherentes a la creación artística cooperativa, como eje vertebrador de la práctica docente a través de las siguientes dimensiones: 1) el engagement y participación activa del alumnado durante el proceso; 2) la adecuación idiomática de los productos artísticos consolidados; 3) la asimilación conceptual del aprendizaje teórico desde metodologías manipulativas; y 4) el grado de aceptación o rechazo de este tipo de música por parte de los estudiantes.

Para acometer el diseño de una propuesta didáctica basada en la creación musical, estilísticamente idiomática e históricamente fundamentada, hemos de tener en cuenta las implicaciones estéticas del repertorio a trabajar, adoptando sus coordenadas teóricas. A continuación, pasamos a describir el marco conceptual que nos ocupa. 


\subsection{Aleatoriedad e indeterminación, las dos caras de una misma moneda}

La inclusión del azar como método composicional entra en escena de la mano de autores como John Cage (1912-1992) a finales de los años 40, en franca oposición al serialismo y a sus férreos principios basados en el racionalismo matemático y la objetividad (Galiana-Gallach, 2018; Castro Alonso, 2020). Así, la aleatoriedad basa su proceso creativo en una toma de decisiones operacionales mediante elementos de azar. Dichos sorteos determinan aquellos elementos de la partitura designados por su autor/a, siendo el intérprete tanto el "generador de aleatoriedad" 1 como el ejecutante (Costa, 2017: 12). Como resultado, el concepto de obra musical tradicional -hasta ahora entendido como ente cerrado en sí mismo- se expande hacia una tipología de manifestaciones artísticas abiertas y cuyo resultado final varía con cada interpretación.

Sin embargo, tal y como admitió el propio Cage, dicha toma de decisiones despersonalizada causa en ocasiones un efecto antinatural, a través de combinaciones sonoras poco idiomáticas o incluso pasajes técnicamente inejecutables (Costa, 2017). Es por todo ello que, a finales de los 50, el músico estadounidense perfila sus presupuestos estéticos hacia un tipo de creación-performativa que revitalice el rol creativo del intérprete: la indeterminación. Acompañada de la proliferación de la notación gráfica, la música indeterminada supone una fragmentación radical con respecto a los conceptos de autoría, obra y partitura establecidos por la tradición clásica occidental, situando al compositor/a al nivel de un oyente más: "se suprime [la] prerrogativa autoral en la definición de la morfología de la obra y en el papel de la partitura como guía estricta que llevaría directamente hacia una determinada sonoridad"2 (Costa, 2017: 8).

Podría decirse, por tanto, que el principal matiz diferenciador entre los conceptos cageanos de aleatoriedad e indeterminación radica en el grado de libertad otorgado al músico/a intérprete. En el caso de la música aleatoria, la partitura y su planteamiento abierto determinan un número amplio -pero limitado- de combinaciones y resultados sonoros posibles. Por su parte, el indeterminismo enfatiza una genuina emancipación creativa de los/las intérpretes, auspiciando "posibilidades ilimitadas"33 (Bernstein, 2014: 557) a la hora de expresar musicalmente las grafías dadas.

\subsection{De lo funcional al estímulo visual: la notación gráfica}

El desarrollo conceptual de la aleatoriedad y la indeterminación -junto con el advenimiento de las músicas electroacústica, electrónica y concreta- implica la redefinición de las fórmulas tradicionales de notación musical a la hora de fijar gráficamente aquellas nuevas sonoridades de siglo (Buj-Corral, 2014; García-Fernández, 2018). La denominada notación gráfica supone una solución a los nuevos requerimientos técnicos y expresivos, representando visualmente aquellas dimensiones del sonido para las que la partitura tradicional no era funcional: aspectos sutiles de la calidad del sonido, gradaciones dinámicas, variaciones rítmicas no mensurables, recursos técnicos

\footnotetext{
${ }^{1}$ Traducido del portugués original.

2 Traducido del portugués original.

${ }^{3}$ Traducido del inglés original.
} 
innovadores o la fijación de aspectos rítmicos o tonales de tradiciones no occidentales (Weekes, 2016). No obstante, la naturaleza pictórica e inmediata de esta tipología de grafía cuestiona el concepto mismo de notación musical. En palabras de GarcíaFernández (2018: 1770), "la grafía ya no es necesariamente un mediador simbólico entre signo y significante (entre grafía y sonido), sino un estímulo visual para el intérprete". Su independencia -y, en cierto sentido, ambigüedad- dan lugar a "interpretaciones múltiples y creativas" en las que "la partitura deja de ser una estructura cerrada y unívoca para convertirse en una proposición abierta" (Buj-Corral, 2014: 279), invitando a la improvisación (Bröndum, 2018).

La operatividad de la notación gráfica como "motor creativo" (García-Fernández, 2018: 1785) posee importantes implicaciones educativas derivadas de su accesibilidad (Barrett, 2001; Weekes, 2016; Viig, 2019). La literatura preexistente suele vincular su integración con el desarrollo cognitivo del individuo, tanto como precursora en la construcción gradual de formas convencionales o informales de representación musical (Weekes, 2016), como en torno a sus capacidades de representación simbólica e indicador del pensamiento musical (Barrett, 2001). Su aplicación en contextos educativos pertenecientes a la educación infantil o primaria deriva del no requerimiento de un bagaje musical previo por parte de sus usuarios/as. En este sentido, "abolir la jerarquía entre intérprete profesional y amateur, entre músicos y "no-músicos", ha sido (...) otra de las motivaciones de los compositores para la creación de partituras gráficas" (Buj-Corral, 2014: 280). Por su parte, el compositor valenciano Llorenç Barber incide en cómo la grafía musical no debiera ser nunca "una barrera simbólica que separe al músico especializado del no músico, sino una experiencia estética al alcance de todos" (GarcíaFernández, 2018: 17859).

\section{METODOLOGÍA}

Esta investigación evalúa una experiencia educativa enmarcada en la enseñanza secundaria postobligatoria (Comunidad Autónoma de Galicia, España), enfocada en promulgar la creatividad y el espíritu crítico de los estudiantes mediante la comprensión y valoración de los referentes artístico-patrimoniales del siglo XX (López-Rodríguez, 2008; Castro Alonso, 2020). Para ello, su diseño experimental responde a una investigación basada en la acción, previa identificación de las necesidades de nuestro grupo de estudio, adoptando un plan de acción de mejora, su observación y posterior reflexión acerca de los resultados acaecidos (Kemmis y McTaggart, 1987).

\subsection{Descripción de la muestra}

La muestra de estudiantes participantes consiste en un grupo de 19 alumnos/as $(n=19)$ de $1^{\circ}$ de Bachillerato, entre los 16 y 18 años. La acción es supervisada por el profesor titular del grupo, contando con la autorización previa del equipo directivo del centro. Asimismo, contamos con el consentimiento informado de las familias y alumnado mayor de edad a efectos de participación en la investigación, con su autorización expresa en la cesión de imagen con propósitos académicos. 
Como primera aproximación a la realidad del grupo, establecemos un período de observación no participante y el inventario de los recursos e instrumental musical disponibles. El proceso de exploración culmina con la realización de un cuestionario inicial $\left(n_{1}=14\right)$ en torno a la valoración discente con respecto al grado de creatividad intrínseco a la materia (preguntas abiertas) y a su experiencia y competencia interpretando música con instrumental Orff (escala Likert de 5 puntos). Si bien el grupo valora positivamente su experiencia en el aula de música, destacando la adquisición de conocimientos técnicos e historiográficos, un $64,29 \%$ de los encuestados reconocen abiertamente como "nada creativa" su experiencia diaria. E1 IES cuenta con un importante fondo con instrumental musical Orff, guitarras acústicas y un teclado, aunque el alumnado posee un autoconcepto competencial "intermedio" en cuanto a su experiencia práctica con los mismos (media de 2,93 sobre 5). Interpretamos, por tanto, cómo la ausencia de un mayor hincapié en la parte práctica e instrumental en su formación podría correlacionarse con la concepción "nada creativa" en el aula. Las tareas de naturaleza reproductiva han de dar paso a aquellas basadas en la producción y la expresión personal, en aras de un mayor engagement discente para con la asignatura.

\subsection{Objetivos de la investigación e instrumentos de recogida de datos}

Conocido el contexto de partida, establecemos los principales objetivos de la investigación, señalando los principales instrumentos de recogida de datos implementados durante el proceso.

- Identificar comportamientos de engagement y participación proactiva en el alumnado. El período de observación inicial constata actitudes y niveles de interés y participación dispares, derivados del enfoque magistrocéntrico que tiende a prevalecer en la enseñanza secundaria postobligatoria. En la presente experiencia se priorizan metodologías interpersonales de trabajo en equipo, a través de las dinámicas del juego e improvisación inherentes a la aleatoriedad y la indeterminación. La recogida de datos cualitativa combinará la observación participante y de vídeo de las sesiones (Viig, 2019).

- Describir y analizar la adecuación idiomática de los productos artísticos creados. Siguiendo los preceptos estéticos de Cage sintetizados en la introducción de este escrito, cada alumno/a actúa como compositor/a -diseñando sus propias notaciones gráficas- al tiempo que como intérprete. Mediante un análisis tanto de grafías (Barrett, 2001; Weekes, 2016; Viig, 2019) como de resultados sonoros (Costa, 2009; Viig, 2019) determinaremos qué tipo de estrategias y procesos creativos han sido los predominantes.

- Comprobar el grado de asimilación teórico-conceptual desde una implementación de metodologías basadas en lo manipulativo. Estudios previos de esta índole sugieren una interiorización del aprendizaje de calidad y duradera con respecto al factor tiempo (Hogenes el al., 2016; Viig, 2019; Castro Alonso, 2020). A través de un cuestionario final ad hoc $\left(n_{2}=19\right)$ estableceremos el grado de asimilación conceptual de las principales coordenadas estético-procedimentales 
de los repertorios musicales trabajados, partiendo de un trabajo eminentemente vivencial y basado en la exploración sonora.

- Conocer el grado de aceptación (o de rechazo) de la música aleatoria e indeterminada por parte del alumnado tras la experiencia. Teniendo en cuenta los procesos cerebrales ante la escucha de este tipo de manifestaciones artísticas (Frova, 2012), así como su mayoritario desconocimiento ante lo minoritario de su público, este estudio pretende conocer la voz de los/las estudiantes tras su inmersión. Para ello, tendremos en cuenta sus reacciones durante el proceso y sus testimonios personales en el cuestionario final.

\subsection{Diseño y planificación de la propuesta práctica}

Pese a los beneficios psicoeducativos inherentes a las tareas de creación musical en el aula -favoreciendo la expresión personal, el trabajo cooperativo, el sentido de pertenencia al grupo, la exploración sonora o el espíritu creativo (Hogenes et al., 2016; Castro Alonso, 2020)-, nos encontramos ante uno de los contenidos más difíciles de planificar y gestionar (Zaragozá, 2009). Durante las sesiones, el profesor/a ha de ejercer un rol de guía, tratando de equilibrar una planificación y secuenciación realistas en sus propuestas con cierta flexibilidad ante posibles imprevistos y/o retrasos derivados del proceso creativo. En todo momento, ha de actuar como modelo de aquellas actitudes que precisamente reclama en el discente, favoreciendo la prosperidad del espíritu crítico y creativo de cada alumno/a. La imposición autoritaria ha de ser desplazada por una postura abierta al diálogo con el/la estudiante, buscando consensos y alternativas personalizadas y aunando esfuerzos de cara a una meta común.

La secuenciación de la propuesta es programada y llevada a cabo en tres únicas sesiones, esquematizadas en la Figura 1. Como comienzo, el alumnado es introducido en la idiosincrasia particular de los principios de aleatoriedad e indeterminación, la ruptura del tradicional eje jerárquico "compositor-intérprete-público" y las repercusiones en la propia forma de anotar la música. Es importante que el/la estudiante amplíe sus horizontes, tal y como señala López-Rodríguez (2008: 2), "sensibilizándose sobre el hecho estético más allá de los estereotipos al uso", reconsiderando las propias ideas de ruido y sonido y, en definitiva, ensanchando su concepto de creatividad. Dicha toma de contacto es acompañada por audiciones y el visionado de ejemplificaciones reales de notaciones gráficas. 


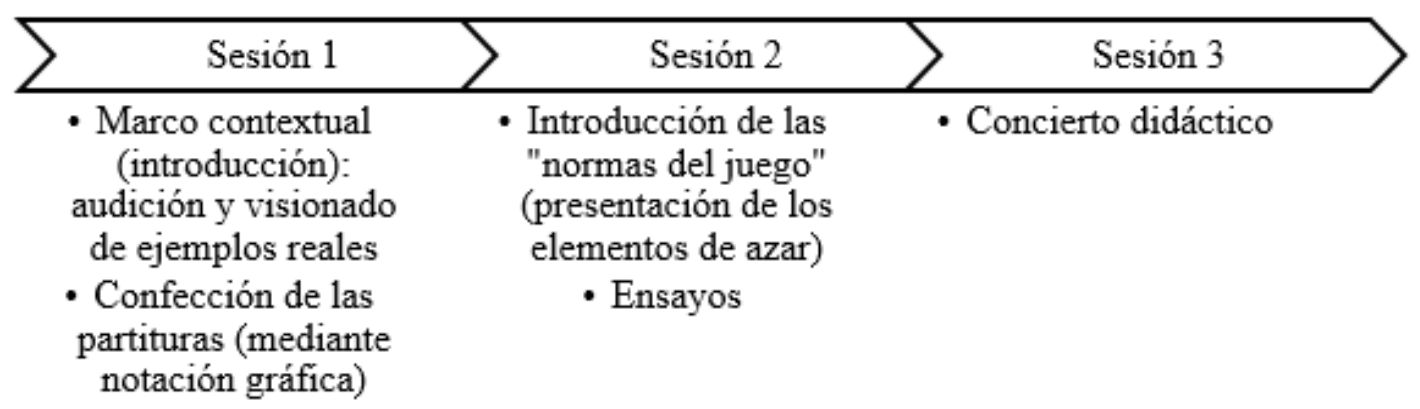

Figura 1. Temporalización de la propuesta práctica

A continuación, se plantea el diseño de las partituras gráficas, previa entrega de una plantilla impresa en folios A4 subdivididos en 6 celdas. En pequeños grupos (2 a 3 individuos), el alumnado acomete colaborativamente la tarea del diseño de una baraja de "naipes musicales", en la que cada carta contiene la información correspondiente a 30 segundos de música. Encontramos ejemplificaciones reales de este tipo de propuesta en piezas como Tarot de Marseille de Bröndum (2018), con una interpretación de 10 segundos por cada carta. Por su parte, el pedagogo Paynter (1999) establece el siguiente símil respecto a la naturaleza como juego de este tipo de repertorio:

Una composición indeterminada se parece un poco a un juego de cartas; existe un marco que se conoce y dentro del cual deben operar los jugadores. También hay elementos fijos - los propios naipes -, pero éstos se cambian de orden y se redirigen de acuerdo con las elecciones y las habilidades de los jugadores (...) los detalles internos de la forma serán distintos cada vez que se juega el juego (Paynter, 1999: 160).

En esta línea conceptual, Costa (2017) explica cómo Cage diseñó durante los años 60 un tipo de piezas musicales de carácter abierto en las que el propio intérprete era "invitado a producir la partitura" (2017: 12), mediante el ordenamiento aleatorio de ítems cerrados y dispuestos en una secuencia en apariencia arbitraria. Nuestra propuesta parte, por tanto, del ordenamiento azaroso de ítems cerrados -las cartas diseñadas en la primera sesión- en una disposición espacial circular de los/as intérpretes. Mediante distintos elementos de sorteo (reparto aleatorio de cartas, dados, monedas y una botella), el alumnado configura su propia partitura (selección de partitura, ordenamiento de sus partes, los silencios y la evolución textural), tal y como se pormenoriza en la Tabla 2.

\footnotetext{
${ }^{4}$ Traducido del portugués original.
} 


\section{Tabla 2}

"Normas del juego": pasos a seguir durante la tarea de creación sonora 30"

\begin{tabular}{ll}
\hline Pasos: & Descripción: \\
\hline $\begin{array}{l}\text { 1. Reparto de cartas } \\
\text { (por el profesor/a) }\end{array}$ & $\begin{array}{l}\text { Disposición del alumnado en círculo. } \\
\text { Reparto aleatorio de las cartas (6 por cada grupo de intérpretes). }\end{array}$ \\
\hline $\begin{array}{l}\text { 2. Tirar un dado } \\
\text { (cada grupo) }\end{array}$ & $\begin{array}{l}\text { Ordenación de las 6 cartas mediante un dado (del 1 al 6) en } \\
\text { sucesivas tiradas. }\end{array}$ \\
\hline 3. Tirar una moneda & Determinación del silencio. Si sale cara, se interpreta la carta. \\
(por cada carta de & Si sale cruz, se silencia (volteamos la carta para evitar \\
cada grupo) & equívocos). \\
\hline 4. Girar una botella & Determinación de la evolución textural de pieza. La botella \\
(por el profesor/a) & señala qué grupo de intérpretes comienza la interpretación. \\
\hline 5. Exploración & Búsqueda de aquellos instrumentos y/o recursos sonoros que \\
sonora (cada grupo) & mejor se adecúen a las cartas a musicar. \\
\hline 6. Ejecución & Proyección de un temporizador a la vista de los intérpretes. En \\
& sentido horario, cada grupo introduce una carta cada 30 \\
& segundos (en el orden previamente establecido). La pieza \\
& finaliza cuando el último grupo interprete su sexta carta. \\
\hline
\end{tabular}

Este concepto de juego, subyacente a la estética cageana, implica la necesidad de que el/la intérprete se adentre "en un universo reglado y ya conceptualmente imaginado a priori"5 (Costa, 2009, 87). La ordenación y disposición de las grafías en una línea temporal (Viig, 2019) mediante dados conforma, en el plano espacial, una disposición en forma de "macro-partitura" circular. En este aspecto, como indica Buj-Corral (2014), las partituras gráficas circulares permiten "incorporar elementos de apertura en la interpretación, tales como la duración de la obra, la elección del sentido de lectura o del punto de comienzo" (2014: 278). En nuestro caso, la función de la botella interpela este aspecto, flexibilizando la evolución textural de la pieza en cada interpretación.

Por otra parte, el silencio desempeña un rol crucial en la obra de Cage, cuyo caso más extremo lo encontramos en su pieza para piano 4'33'”. La adopción de la moneda contribuye a espaciar el discurso musical, evitando el "espeso cenagal sonoro" (Schafer, 1986: 34) resultante de la continua acción conjunta de todos los grupos simultáneamente. Este tipo de problemáticas habrían sido resueltas por Cage en el pasado en piezas como Musicircus, evitando que los músicos/as quedasen sepultados por la propia textura general de la pieza (Costa, 2017). Como homenaje a la obra mencionada anteriormente y dada la importancia de la estructuración de nuestro diseño en fragmentos de 30 segundos- el grupo decide titular la propuesta como 30 ”.

Finalmente, la propuesta culmina con un concierto didáctico consistente en una doble interpretación de la pieza 30" ante compañeros/as de otros cursos y demás miembros de la comunidad educativa. En este sentido, "siempre que sea posible, los

\footnotetext{
${ }^{5}$ Traducido del portugués original.
} 
estudiantes deben poder sentir que han hecho algo que esté completo en sí" (Paynter, 1999: 27), como modo de alcanzar una mayor significación en la propuesta, así como una medición final del nivel de compromiso alcanzado como grupo.

\section{RESULTADOS}

Subdividimos los datos recabados según los siguientes apartados: el análisis visual de las notaciones gráficas producidas, las lecturas desprendidas de su interpretación musical y la valoración de las informaciones obtenidas en el cuestionario final.

\subsection{Análisis y clasificación de las notaciones gráficas}

El estudio de las imágenes incluidas en las notaciones gráficas proporciona una fuente flexible a la hora de reconocer tanto formas de representación de eventos musicales (Weekes, 2016), como los condicionamientos culturales y socio-comunitarios del alumnado (Viig, 2019). Un rasgo común en este tipo de estudios -mayormente enfocados en niños/as- radica en el amplio rango de estrategias notacionales empleadas: el recurso a iconos, pictografías, símbolos musicales convencionales o prestados de otros dominios (palabras, letras, números, signos de dirección, etc.), además de signos de nueva invención (Barrett, 2001). Notaciones que, por cierto, poseen elementos de naturaleza polisémica, variando sus significaciones según su creador/a o intérprete (Buj-Corral, 2014), lo cual da muestras de la ardua tarea en su estudio y codificación.

A efectos de comprender su realidad de estudio, Barrett (2001) establece una categorización de las grafías que responde a las estrategias de representación implementadas por el alumnado. Siguiendo a Viig (2019), establecemos nuestro propio análisis en función de la comparativa con dichas categorías. En primer lugar, existe un predominio cuantitativo de cartas con representaciones simbólicas, esto es, con el recurso a símbolos específicos en correspondencia directa hacia sonidos concretos. De un total de 48 cartas, las líneas $(60,42 \%)$ y los puntos $(39,58 \%)$ de diversas morfologías se combinan en un 79,17\% (Figura 3). Desde un enfoque teórico socio-semiótico, Weekes (2016) diferencia el significado de las imágenes en cuanto a sus dimensiones musicales referidas. Desde esta óptica, clasificamos dichos matices diferenciadores en la aplicación de las líneas y puntos, tal y como se refleja en la Tabla 4. 

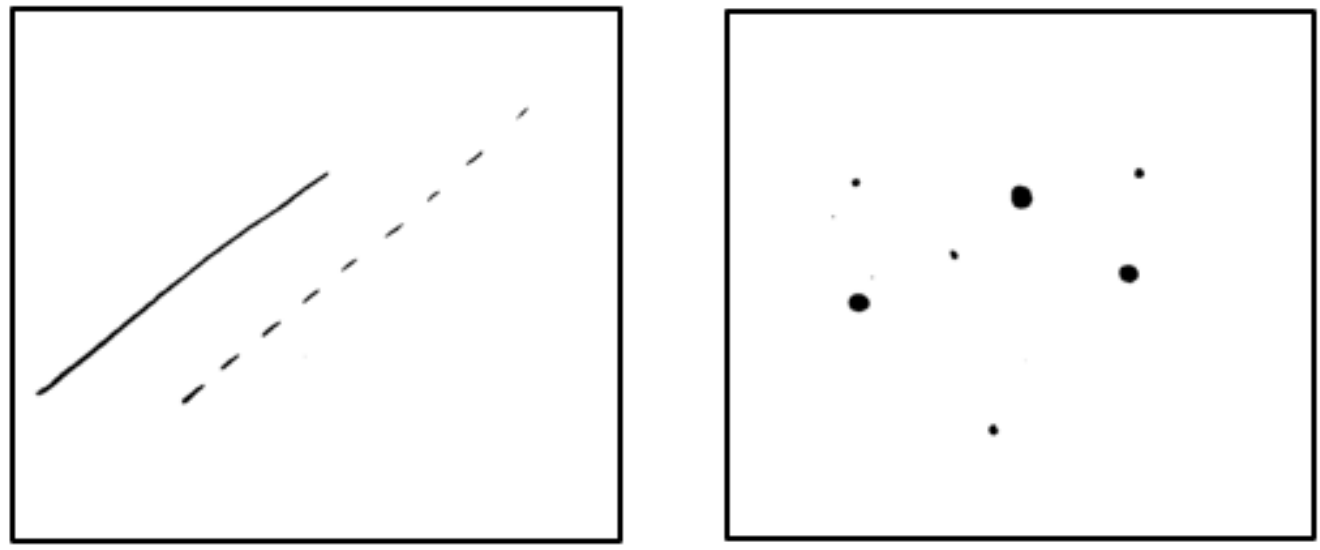

Figura 3. Ejemplos de representaciones simbólicas: líneas y puntos

\section{Tabla 4}

Clasificación e índice de utilización de las grafias basadas en líneas y puntos. Clasificación de significado según Weekes (2016)

\begin{tabular}{|c|c|c|c|}
\hline Signo & Imagen & $\begin{array}{l}\text { Índice de } \\
\text { utilización }\end{array}$ & $\begin{array}{l}\text { Aspecto del } \\
\text { significado }\end{array}$ \\
\hline \multirow{4}{*}{ Línea/s } & Líneas rectas & $31,25 \%$ & \multirow{3}{*}{$\begin{array}{c}\text { Contornos melódicos } \\
\text { y dinámicas }\end{array}$} \\
\hline & Líneas curvas & $14,58 \%$ & \\
\hline & Líneas circulares & $4,17 \%$ & \\
\hline & Líneas discontinuas & $10,42 \%$ & $\begin{array}{c}\text { Contornos melódicos } \\
\text { y rítmica }\end{array}$ \\
\hline \multirow{4}{*}{ Punto/s } & Puntos uniformes aislados & $20,83 \%$ & \multirow{3}{*}{$\begin{array}{l}\text { Contornos melódicos, } \\
\text { rítmica y articulación }\end{array}$} \\
\hline & Puntos heterogéneos aislados & $6,25 \%$ & \\
\hline & Grupos de puntos uniformes & $2,08 \%$ & \\
\hline & Grupos de puntos heterogéneos & $10,42 \%$ & $\begin{array}{l}\text { Contornos melódicos, } \\
\text { rítmica, articulación y } \\
\text { estructura formal }\end{array}$ \\
\hline
\end{tabular}

En segundo lugar, destacamos la presencia de representaciones con simbología adoptada, en este caso con la inclusión de onomatopeyas en $27,08 \%$ del total, bien sea en solitario o en combinación de puntos y/o líneas. En esta tipología de cartas, la disposición del texto varía, sugiriendo en ciertos casos contornos melódicos o actuando como subtexto de otros símbolos (Figura 5). 

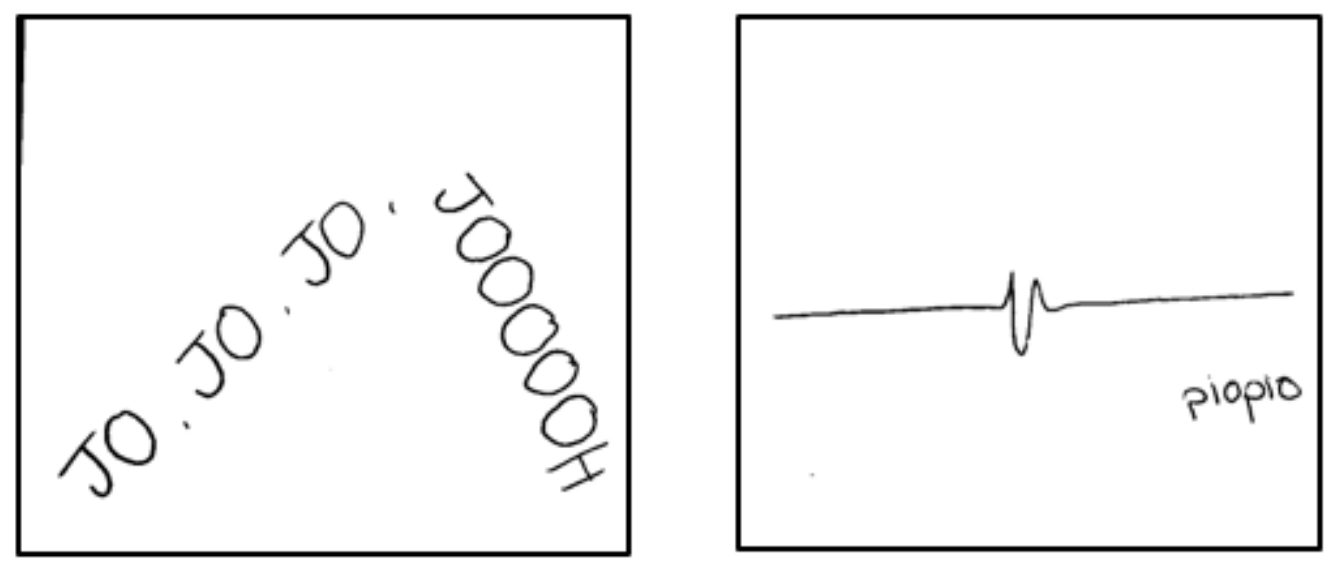

Figura 5. Ejemplos de representaciones con simbología adoptada

En tercer lugar, destacamos aquellas representaciones exploratorias que, mediante el recurso gráfico de dibujos azarosos como garabatos y tachones $(8,33 \%)$, establecen una relación poco concreta o directa entre símbolo y sonido, pudiendo sugerir interpretaciones vinculadas al contorno melódico, la textura, la rítmica o la dinámica. Por último, mencionamos la presencia de un caso de representación enactiva, mediante un dibujo que refleja una acción o gesto sonoro directo a través del papel. Agregamos ejemplificaciones de estas últimas dos categorías en la Figura 6.
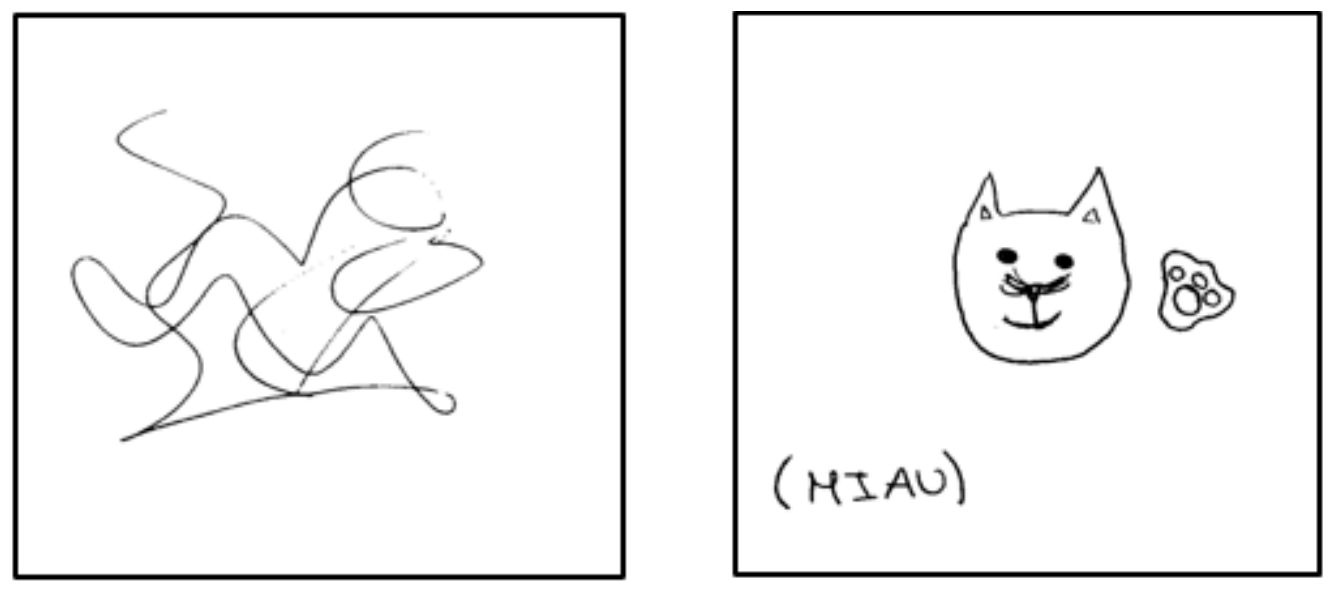

Figura 6. Ejemplos de representación exploratoria y enactiva

En lo relativo al resto de estrategias notacionales resultantes de los estudios de Barrett (2001) y Viig (2019) -las representaciones de instrumentos o de instrumentos modificados mediante dibujos o esbozos-, no encuentran su testimonio en nuestra muestra. La preponderancia de las representaciones simbólicas lineales, los puntos y la geometría son inherentes a la idiosincrasia de nuestro grupo de estudio, en relación con los estudios mencionados, con una población enmarcada en la educación infantil y primaria. No obstante, la selección de símbolos nos permite atisbar, en cierto sentido, ciertos referentes socioculturales relativos a la formación o experiencia previa de nuestro 
grupo (Viig, 2019), incluyendo aspectos identitarios. Prueba de ello han sido el carácter humorístico en ciertas onomatopeyas (“JO, JO, JO, JOOOOOH”, “¡iGUAAAU!!”, "EPA", "OING OIGN OING OING", etc.) o la inclusión de la letra del estribillo de una popular canción (“SAMBA DA BAÍA”).

\subsection{Interpretación musical de las grafías y descripción del proceso creativo}

Este análisis toma como punto de partida las dos interpretaciones finales durante el concierto didáctico, pretendiendo alcanzar una comprensión del proceso creativo en retrospectiva (Viig, 2019). Mediante el visionado del material audiovisual recabado, transcribimos cada una de las interpretaciones según los siguientes criterios: 1) el tipo de respuestas musicales a las grafías dadas: diseños rítmico-melódicos, dinámicas, texturas, estructuración del discurso musical y recursos técnicos incorporados; 2) la elección de instrumental musical y la inventiva en las estrategias de exploración sonora; y 3) la gestualidad, advirtiendo el grado de participación, concentración y la escucha atenta y respetuosa del compañero/a. Durante el proceso de trascripción recurrimos tanto a la simbología tradicional de notación como al texto escrito (Viig, 2019), procediendo según marcas temporales de vídeo de 30 segundos de forma sistemática.

Durante las actuaciones finales, un presentador dinamiza y explica los procesos aleatorios que están teniendo lugar ante el público, procediendo en directo según las "normas del juego" enunciadas en la Tabla 2. Cada uno de los 8 grupos de intérpretes dispone de un tiempo para configurar sus cartas y predeterminar el tipo de respuesta creativa tomada al respecto. Cage defendía un compromiso basado en la disciplina y el respeto para con el autor/a de la partitura, mas por ello sin dejar de tener la libertad de ser uno mismo/a (Costa, 2017). Asimismo, destacaba la necesaria capacidad del intérprete a la hora de ser independiente, de ser capaz de "desligar la mente"6 (Costa, 2017: 11), desaconsejando la búsqueda de una coordinación artificial con el resto de músicos/as durante las ejecuciones, en aras de un mayor rigor personal.

La codificación de las estrategias musicales durante el proceso permite categorizar dos principales comportamientos en el alumnado de muestra. Describimos, a continuación, las dos principales tipologías:

- Mímesis de la grafía a través de movimientos motrices. En esta categoría incluimos aquellas repuestas basadas en la imitación gestual de grafías (líneas, puntos, garabatos, etc.) mediante una técnica instrumental o vocal focalizada en dicha intención descriptiva. En este tipo de casos, el resultado sonoro final pasa a ser secundario. No se pretende alcanzar un ideal estético de "belleza" o ni siquiera "musical": se favorece, por el contrario, un tipo de sonoridades improvisatorias, experimentales y azarosas, habitualmente desincronizadas, sin relieve dinámico y que parten de planteamientos previos no solfeísticos. Entre las soluciones técnicas implementadas en este tipo de respuestas destacamos tres: 1) la imitación de notaciones basadas en puntos con instrumentos de placas, a través de una técnica "puntillista" de sonidos aleatorios aislados, más o menos continuos según la

\footnotetext{
${ }^{6}$ Traducido del portugués original.
} 
densidad de la grafía e incluyendo acentuaciones según los tamaños de los mismos; 2) la "técnica de dibujado", a través de movimientos espontáneos de baquetas sobre los instrumentos de láminas a la hora de representar tanto líneas de izquierda a derecha (glissandi), de arriba abajo (perpendicularmente a las placas) o garabatos (con movimientos azarosos); y 3) la "técnica de clúster-oruga" llevada a cabo en el teclado, combinando un movimiento ondulatorio y transversal de la palma de la mano sobre el teclado, en imitación a las líneas curvas.

- Acomodación de la grafía a los condicionamientos del background sociocultural. En este caso, el alumnado adapta sus interpretaciones hacia metas sonoras basadas en lo solfeístico (escalas definidas nota a nota, sensación de pulso, subdivisión, etc.) y la convención (acordes, consonancias, construcción de melodías sobre acompañamientos, etc.). En este sentido, la prevalencia se sitúa en producir resultados sonoros "agradables" -desde un punto de vista de la tradición musical occidental- por parte de un sector del alumnado que presenta cierto bagaje y experiencia musical previa (Bröndum, 2018). Los resultados sonoros adquieren un carácter improvisatorio menos acentuado que en la anterior categoría, mediante soluciones fijadas previamente por parte de cada grupo de intérpretes: destaca su mayor grado de sincronización rítmica, ciertas incursiones en el terreno de la exploración dinámica y una mayor determinación en las alturas concretas de los sonidos escogidos.

La elección de instrumentos musicales u otros recursos sonoros por parte de los estudiantes condiciona, en la mayoría de casos, su tipo de respuestas. Es el caso de los instrumentos de percusión de afinación indeterminada, cuyo uso conduce hacia una simplificación de patrones rítmicos -cuaternarios, de concepción solfeística- en nuestra muestra. Por lo general, los instrumentos de láminas y el teclado consolidan tipos de respuesta más innovadoras e ingeniosas, permitiendo mimetizar contornos melódicos directamente mediante gestos motrices. La presencia de guitarras y de un violín enriquecen las improvisaciones, a través de técnicas como el glissandi, el slap o el pizzicato.

El desarrollo del concierto didáctico permite también comprobar el grado de participación y engagement alcanzado por el grupo. Durante la práctica, prevalece la complicidad y el ambiente distendido, especialmente en los casos de respuestas basadas en la mímesis gráfica a través de lo motriz y en las onomatopeyas. En las sesiones iniciales, la oportunidad de experimentar con recursos pictóricos y sonoros es acogida positivamente por el grupo, generando una atmósfera de alegría que se logra transmitir al público durante la audición final. Por otra parte, la naturaleza como juego de la experiencia y lo imprevisible de sus resultados sonoros hacen que se potencie la escucha atenta y el interés hacia las producciones de los compañeros/as, tal y como se refleja en la gestualidad de los participantes (Figura 7). 


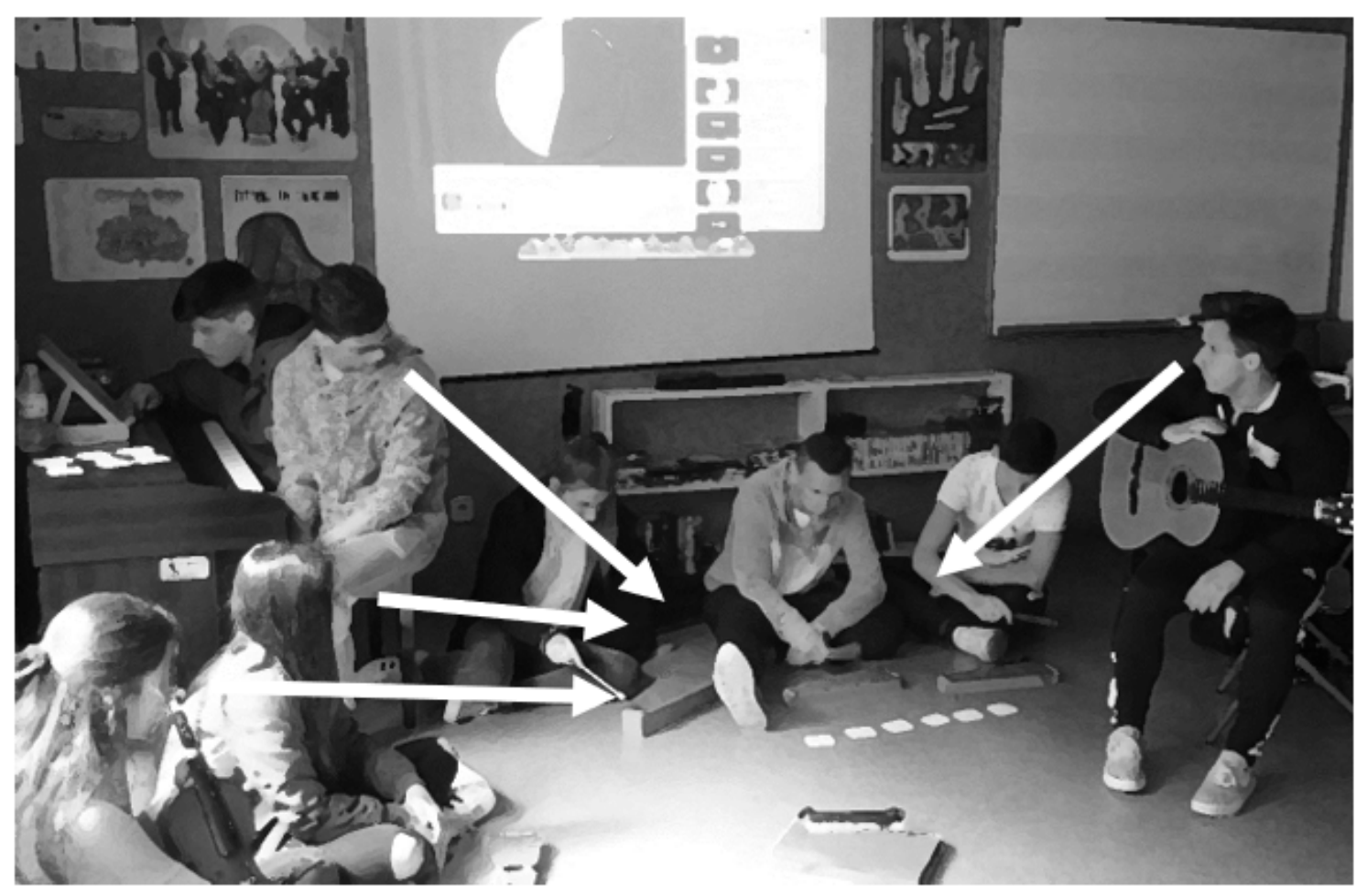

Figura 7. Fotograma de la grabación en vídeo del concierto didáctico: ejemplo de atención y escucha atenta

Asimismo, la transcripción de las tomas de vídeo nos permite categorizar ciertas conductas que corroboran el compromiso del grupo frente a los ensayos precedentes. La presencia del público optimiza los niveles de atención, alcanzando versiones mucho más adecuadas a los principios de disciplina enunciados por Cage (Costa, 2017). Los desajustes y faltas de concentración precedentes dan paso a versiones rigurosas estructuralmente, la anticipación preventiva y un mayor respeto por el silencio. La toma de consensos se torna más funcional y efectiva, fruto de un mayor dominio de la idiomática del repertorio y de las posibilidades de los instrumentos escogidos, así como de una capacidad de diálogo más fluida. Coincidiendo con Viig (2019), el menor bagaje instrumental de cierto sector de alumnos/as se traduce en miradas al profesor, en la búsqueda de la aprobación de sus intentos. Progresivamente, los nervios e indecisiones son paliados mediante la acción espontánea de un grupo de líderes, quienes mediante gestos o miradas coordinan las actuaciones tanto en pequeño como en gran grupo.

\subsection{Aprendizaje y perspectiva del alumnado}

La experiencia de campo en esta investigación-acción culmina con la realización de un cuestionario final $\left(n_{2}=19\right)$, a través del cual conoceremos el nivel de asimilación conceptual y el grado de aceptación de la experiencia por parte de los estudiantes. El primer grupo de ítems (cuestiones de múltiple respuesta) responde a los siguientes cuatro bloques temáticos: 1) principios estéticos de la aleatoriedad e indeterminación: concepto de libertad del intérprete frente a su rol tradicional; 2) su naturaleza imprevisible y abierta: 
multiplicidad de resultados según los designios del azar; 3) contexto y relevancia de John Cage; y 4) origen e implicaciones de las nuevas notaciones gráficas. En la Figura 8 se refleja el índice de respuestas positivas y negativas con relación a cada bloque de preguntas.

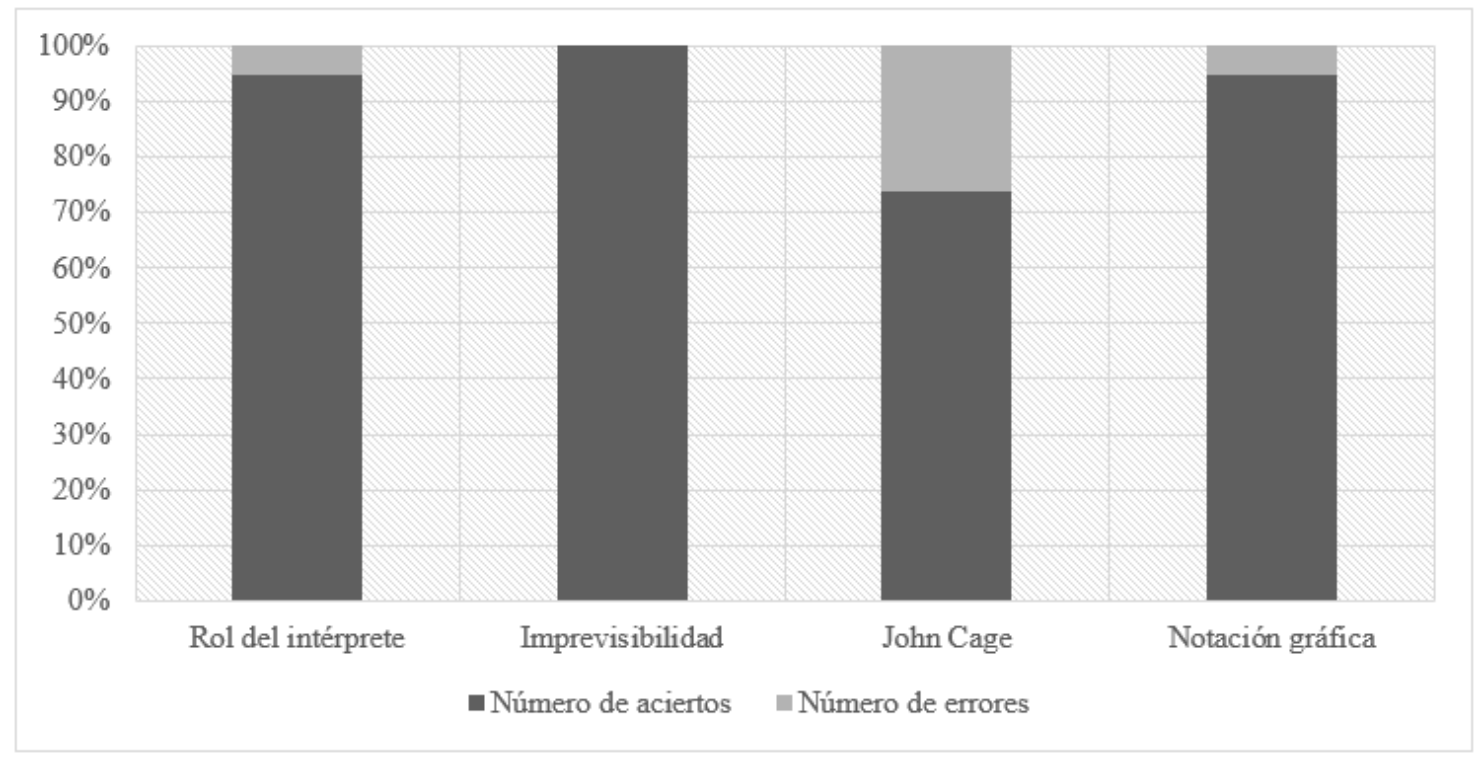

Figura 8. Índice de errores y aciertos en el cuestionario final (parte teóricoconceptual)

A partir de estos resultados podemos inferir cómo precisamente el bloque de preguntas 3, de carácter más puramente biográfico o historiográfico, ha sido el peor asimilado (73,68\% de aciertos). Son, precisamente, aquellas cuestiones más directamente demostrables a través de la práctica las que han consolidado un mayor grado de aciertos por parte del alumnado (entre un $94,74 \%$ y un $100 \%$ ). Estos resultados constatan la calidad de un aprendizaje conceptual basado en la manipulación vivencial de lo estudiado, desde la creación artística y la promoción de la libre expresión personal, al menos en el corto plazo.

Dichos datos son complementados con las valoraciones y testimonios discentes recogidos en la segunda parte del cuestionario (preguntas abiertas). El potencial didáctico y motivacional de la experiencia es reconocida por los propios adolescentes: "sirve para entender la música aleatoria de una manera más divertida", "entretenido" o "aprendí muchas cosas". Agradecen efusivamente la libertad otorgada, así como lo innovador y creativo de la propuesta: "pudimos interpretar la música como quisimos", "sin saber lo que iba a sonar", "no está atado a una pauta, es abierto" o "despliega la imaginación e improvisación del alumno". Estos comentarios refrendan la interiorización significativa del repertorio estudiado desde el recurso a metodologías activas basadas en la creatividad y el trabajo en equipo. Asimismo, subrayan una aceptación muy positiva de la experiencia (con un valor cuantitativo de 9.25 sobre 10), destacando su utilidad como incentivo hacia el interés por repertorios desconocidos. Finalmente, los alumnos/as resaltan la experiencia durante el concierto ("nunca había hecho algo así", "emocionante", "un gran recuerdo" o 
"salió muy bien"), agradeciendo la oportunidad de "enseñarle a la gente de otro curso lo que habíamos creado en clase".

\section{DISCUSIÓN}

El presente estudio se articula en torno a la hipótesis de que un repertorio -a priori desconocido o minoritario- como el de la aleatoriedad y la indeterminación podría ser comprendido e incluso disfrutado desde una aproximación basada en la creación artística. Hacia ese fin planificamos una experiencia de inmersión, articulada según unas "reglas del juego" fundamentadas estética e historiográficamente y orientada según cuatro objetivos de investigación sobre los que reflexionaremos a continuación.

Con respecto a la identificación de comportamientos de engagement y participación proactiva en el alumnado, la propuesta de acción adaptada a las necesidades del grupo cumple su cometido, en la línea de investigaciones previas como las de Hogenes et al. (2016) o Castro Alonso (2020). El incentivo hacia la libre expresión personal, la improvisación y el juego como ejes del proceso de enseñanza-aprendizaje sorprenden al alumnado de bachillerato en un primer momento. Es de vital importancia, en este punto, reseñar una vez más la importancia del rol del educador/a como adalid del espíritu creativo, encauzando los esfuerzos colectivos hacia metas comunes. La experiencia final ante público actúa como revulsivo, de cara a un compromiso por ofrecer la mejor versión posible, inclusive entre el alumnado más disruptivo. La implicación de dinámicas de ayuda y de liderazgo entre iguales, así como el genuino interés y respeto por las producciones de los compañeros/as, son comportamientos afines hacia ese engagement, difícilmente alcanzable desde presupuestos exclusivamente basados en lo expositivo (Hogenes et al., 2016).

El grado de cumplimiento del segundo objetivo -describir y analizar la adecuación idiomática de los productos artísticos creados- comporta discernir en qué medida el alumnado ha comprendido el concepto estético y procedimental específico, según el cumplimiento de las consignas promulgadas. La prevalencia de representaciones simbólicas y de representaciones con simbologías adoptadas (Barrett, 2001; Viig, 2019) en las notaciones gráficas elaboradas denotan una imitación estilística de los modelos reales expuestos durante el preámbulo de la propuesta, pero también dan muestra de la personalidad y de ciertos rasgos identitarios de sus autores/as. Como propuestas de reformulación para futuras investigaciones, podría incentivarse el uso del color en las grafías, el añadido de instrucciones textuales que contribuyan a una interpretación más acorde a los designios de su autor/a o la presencia de sistemas de anotación gráfica basados en tablas de estructura o gráficos de dinámicas (Weekes, 2016).

En lo relativo a las interpretaciones musicales per se, encontramos comportamientos en el alumnado acordes a los conceptos de disciplina e independencia promulgados por Cage (Costa, 2017). Es en el caso de aquellas interpretaciones basadas en la mímesis de la grafía a través de movimientos motrices en las que se obtienen ejemplos sonoros más idiomáticos estilísticamente: la búsqueda de soluciones técnicas imaginativas, su impredecibilidad o la independencia rítmica de los grupos dan fe de ello. 
Por su parte, aquellas ejecuciones basadas en la acomodación de la grafía a los condicionamientos del background sociocultural denotan una intención idiomática en diferente término: si bien los resultados sonoros pierden cierta frescura e independencia, surgen de un mayor compromiso con la disciplina cageana (Costa, 2017), al tiempo que nos permiten entrever rasgos de las influencias y de los referentes educativos y culturales del alumnado.

Como en toda investigación-acción, los resultados de este artículo quedan delimitados a la realidad de nuestra muestra de estudio, pudiendo o no ser extrapolables a otros contextos educativos. La evaluación del tercer objetivo -comprobar el grado de asimilación teórico-conceptual desde una implementación de metodologías basadas en lo manipulativo- parte de este límite de alcance, sin pretender ser conclusivos en este aspecto. No obstante, coincidimos con estudios previos (Hogenes et al., 2016; Castro Alonso, 2020) a la hora de constatar los beneficios inherentes de este tipo de aproximación metodológica, incidiendo en que los índices de asimilación patentes en el cuestionario final difícilmente habrían sido posibles desde una aproximación puramente magistrocéntrica o basada en la abstracción teórica. Sirvan de ejemplo los resultados alcanzados por los estudiantes, como un acicate para el profesorado a la hora de introducir dinámicas participativas y basadas en la creación. Es posible aprender disfrutando, inclusive con alumnado de bachillerato.

Por último, respecto al cuarto objetivo -conocer el grado de aceptación (o de rechazo) en la música aleatoria e indeterminada por parte del alumnado tras la experiencia-, reconocemos que la propia naturaleza y límites de estos repertorios son todavía causa de debate en los círculos académicos. Costa (2009) cuestiona la libertad otorgada al músico/a intérprete en la indeterminación, aludiendo un encorsetamiento hacia unas reglas de juego predefinidas, arbitrarias y externas, promulgadas por el compositor/a. Como consecuencia, el propio resultado auditivo se vuelve secundario o irrelevante, propiciando ambientes sonoros poco acogedores para la improvisación libre. Sin embargo, para Buj-Corral (2014) son precisamente los nuevos grafismos los que liberaron la imaginación de ciertos improvisadores/as, más allá de clichés y esquemas, exponiendo al intérprete a nuevos horizontes. Por su parte, el compositor Bröndum (2018) defiende que improvisación y notación no son excluyentes: la notación gráfica en sus obras responde a una retención de sus ideas como creador y como una invitación al diálogo entre compositor/a e intérprete durante el proceso musical. Desde un punto de vista educativo, a la hora de abordar tareas de creación musical hemos de tratar de orientar a nuestro alumnado con consignas (Gainza, 1983) que acoten, en cierta manera, el abrumador campo de la libertad total. El repertorio de la aleatoriedad y de la indeterminación ofrecen, bajo nuestra experiencia, una hoja de ruta clara, al tiempo que propugna una apertura de oídos hacia sonoridades experimentales e innovadoras de nuestro patrimonio.

Coincidimos con López-Rodríguez (2008: 3) en señalar que "tal vez solo sea una cuestión de prejuicio considerar como natural la dificultad de aceptación de ciertos lenguajes por parte de los alumnos en la adolescencia, haciéndonos partícipes de un prejuicio bastante generalizado". Pese a su distanciamiento respecto a la música que consumen los adolescentes en su día a día, el tipo de reacciones y comentarios suscitados 
por la aleatoriedad y el indeterminismo durante esta investigación así lo confirman. Asimismo, la notación gráfica demuestra su potencial, proporcionando un recurso pedagógico inclusivo abierto a cualquier condición, con independencia del bagaje musical previo del alumnado (Paynter, 1999; Viig, 2019). La continuidad en las investigaciones de esta índole podría contribuir hacia una enseñanza musical que favorezca la apertura de horizontes sonoros y culturales (López-Rodríguez, 2008), desde una comprensión basada en lo vivencial y permitiendo consolidar composiciones estilísticamente idiomáticas en el aula de secundaria.

\section{REFERENCIAS BIBLIOGRÁFICAS}

Barrett, M.S. (2001). Constructing a View of Children's Meaning-Making as Notators: A Case-Study of a Five-Year-Old's Descriptions and Explanations of Invented Notations. Research Studies in Music Education, 16(1), 33-45. https://doi.org/10.1177/1321103X010160010401.

Bernstein, D.W. (2014). John Cage's Cartridge Music (1960): A Galaxy Reconfigured. Contemporary Music Review, 33(5-6), 556-569. https://doi.org/10.1080/07494467.2014.998419.

Bröndum, L. (2018). Graphic Notation, Indeterminacy and Improvisation: Implementing Choice Within a Compositional Framework. Open Cultural Studies, 2(1), 639-653. https://doi.org/10.1515/culture-2018-0058.

Buj-Corral, M. (2014). Partituras Gráficas Circulares: Entre Tiempo y Espacio. Barcelona Investigación Arte Creación, 2(3), 277-300. https://hipatiapress.com/hpjournals/index.php/brac/article/view/985.

Castro Alonso, V. (2020). Tras la estela pedagógica de Schönberg: el dodecafonismo como medio de composición musical en el aula de Secundaria. DIGILEC: Revista Internacional de Lenguas y Culturas, 7, 29-48. https://doi.org/10.17979/digilec.2020.7.0.7104.

Costa, R.L.M. (2009). A idéia de jogo em obras de John Cage e no ambiente da libre improvisaçao. Per Musi, 19, 83-90. https://doi.org/10.1590/S151775992009000100009.

Costa, V.F. (2017). O lugar da performance na música indeterminada cageana. Revista Música Hodie, 17(1), 7-18. https://doi.org/10.5216/mh.v17i1.46422.

Frova, A. (2012). Audience reluctance in the face of twentieth century avant-garde music. Rend. Fis. Acc. Lincei, 23, 289-293. https://doi.org/10.1007/s12210012-0170-8.

Gainza, V.H. (1983). La improvisación musical. Buenos Aires: Ricordi.

Galian-Gallach, J.L. (2018). De la naturaleza de la improvisación libre: elementos esenciales para su identificación y diferencias con la composición escrita. ITAMAR. Revista de Investigación Musical: Territorios para el Arte, 4, 26-49. https://ojs.uv.es/index.php/ITAMAR/article/view/12880.

García-Fernández, I.D. (2018). Estrategias para el análisis de la música visual: el caso de Llorenç Barber. En Musicología en el siglo XXI: nuevos retos, nuevos 
enfoques, B. Lolo y A. Presas (eds.), 1769-1785. Madrid: Sociedad Española de Musicología.

Hogenes, M., Oers, B., Diekstra, R.F.W., y Sklad, M. (2016). The effects of music composition as a classroom activity on engagement in music education and academic and music achievement: A quasi-experimental study. International Journal of Music Education, 34(1), 32-48. https://journals.sagepub.com/doi/abs/10.1177/0255761415584296.

Kemmis, S. y McTaggart, R. (1987). Cómo planificar la investigación-acción. Barcelona: Laertes.

López-Rodríguez, J.M. (2008). Aprendiendo a través de la indeterminación. LEEME, 22, 1-14. https://ojs.uv.es/index.php/LEEME/article/view/9776.

Paynter, J. (1999). Sonido y estructura. Madrid: Akal

Schafer, R. M. (1986). El compositor en el aula. Buenos Aires: Ricordi.

Viig, T. (2019). There is a shark coming, then there is a du-du-du-du-du...: Mediating cultural tolos in a Norwegian creative music-making Project. British Journal of Music Education, 36(2), 125-138. https://doi.org/10.1017/S026505171900007X.

Weeks, T. (2016). Mastering musical meaning: images as interpretive resources in multimodal music texts. Visual Communication, 15(2), 221-250. https://doi.org/10.1177/1470357215622737.

Zaragozá, J. L. (2009). Didáctica de la música en la educación secundaria. Competencias docentes y aprendizaje. Barcelona: Graó. 